\title{
Spatial-temporal Distribution Characteristics of Snow Depth in Mongolian Plateau Based on Reanalysis Data
}

\author{
Lai Quan ${ }^{1,2,3}$, Yulong Bao ${ }^{1}$, Yongbin Bao ${ }^{3}$, Sa Chula ${ }^{1, *}$, Yuhai Bao ${ }^{1}$ \\ ${ }^{1}$ College of Geographical Science, Inner Mongolia Normal University, Hohhot010022, China \\ ${ }^{2}$ Inner Mongolian Key Laboratory of Remote Sensing and Geographic Information System, Inner \\ Mongolia Normal University, Hohhot010022, China \\ ${ }^{3}$ School of Environment/Natural Disaster Research Institute, Northeast Normal University, \\ Changchun130024, China \\ 基于在分析数据的蒙古高原雪深时空特征分析 \\ 来全 ${ }^{1,2,3}$, 包玉龙 ${ }^{1}$, 包勇斌 ${ }^{1}$, 萨楚拉 ${ }^{1, *}$, 包玉海 ${ }^{1}$ \\ ${ }^{1}$ 内蒙古师范大学地理科学学院, 呼和浩特 010022 , 中国 \\ ${ }^{2}$ 内蒙古自治区遥感与地理信息系统重点实验室, 呼和浩特 010022, 中国 \\ ${ }^{3}$ 东北师范大学环境学院/自然灾害研究所, 长春 130024 , 中国
}

\begin{abstract}
In this paper, using the 1980-2015 ECMWF reanalysis data, the MVC method was used to obtain the monthly snow depth. Combined with trend analysis, 5a moving average, abnormal year analysis and MK mutation test, we analyze the spatio-temporal characteristics of snow depth and it influencing factors in the Mongolian Plateau. The results showed that: (1) the snow depth of the Mongolian Plateau increased at $0.25 \mathrm{~mm} / \mathrm{a}$, particular after 2000, but there was no obvious mutation. And the minimum snow depth during the year occurred in October and reached the maximum in February of the following year. (2) Abnormal deep snow depth is mainly occurred in the $21 \mathrm{st}$ century, especially after 2009 , indicating that it has been in snowy periods. (3) On the spatial distribution, the snow depth of the Mongolian Plateau increases from south to north and from
\end{abstract}

*通讯作者: 萨楚拉（1977-）, 男, 博士, 副教授, 主要从事遥感与地理信息系统应 用研究。Emai1: sachulan@126.com。 west to east. (4) Snow depth in Mongolian Plateau is mainly affected by temperature and precipitation.

Keywords: snow depth; Mongolian Plateau; meteorological factors; spatial-temporal characteristics

\section{摘要}

本文利用 1980-2015 年 ECMWF 再分析 数据, 按最大合成法得到月尺度雪深数据, 结合趋势分析法、 $5 \mathrm{a}$ 滑动平均法、异常年 份分析及 MK 突变检验, 分析了蒙古高原雪 深的时空变化特征, 并讨论了其影响因素。 结果表明:（1）时间变化上，1980-2015 年 间蒙古高原雪深以 $0.25 \mathrm{~mm} / \mathrm{a}$ 的速率呈增加 趋势, 2000 年后增加幅度更明显, 但无明 显的突变特征。年内雪深最小值出现在 10 月, 次年 2 月达到最大值。(2) 雪深的异 常偏多年份主要集中在 21 世纪, 尤在 2009 年之后, 说明近几年处于多雪期。(3) 空 间分布上, 蒙古高原雪深有明显的空间差 异性, 呈由南向北、由西向东增加的特征。 (4) 蒙古高原雪深主要受气温和降水的影 


\section{A}

响。

关键词: 雪深; 蒙古高原; 时空特征; 气 象因子

\section{1. 引言}

积雪是由降雪及风吹雪搬运与堆积形 成的覆盖在地球表面的雪层 ${ }^{[1]}$ 。一方面, 积 雪的空间分布可以极大地影响地表能量收 支和气候变化。另一方面, 季节性融雪是 干旱半干旱地区的主要水源 ${ }^{[2]}$, 但由冬季积 雪过厚或高山融雪引起的自然灾害会严重 造成当地的损失。进而影响此地区的水资 源利用、农牧业、牧草返青期和自然灾害 发生情况, 是限制草原发展的重要影响因 素。因此研究其雪深时空分布具有重要的 水文、气候和生态意义。

自 20 世纪 90 年代以来, 随着卫星遥 感的发展目前研究主要集中于积雪面积监 测或雪深反演模拟上, 如哈斯、Huang X 等 学者 ${ }^{[2,3]}$ 利用 MODIS 产品, 探讨了积雪面积 的时空分布及其与气象和海拔的相互关系。 戴声佩等 ${ }^{[4]}$ 利用被动微波遥感反演雪深并分 析了其时空动态趋势及异常变化。王芹芹、
王国强等学者 ${ }^{[5,6]}$ 利用雪深实测数据研究了 雪深变化规律及其与气象因子之间的关系。 总体来说, 学者们主要通过 MODIS 产品、 被动微波遥感、SSM/I 及传统的实地观测方 法来研究积雪。但这不能提供长时间序列 的数据, 而 $\mathrm{ECMWF}$ 能提供历史积雪观测数 据集 ${ }^{[7]}$ 。且当前研究主要集中于西北和青藏 高原, 并未涉及到蒙古高原。

因此, 本文利用 1980-2015 年 ECWWF 再分析数据, 采用趋势分析、滑动平均及 MK 突变等方法分析了蒙古高原地区雪深的 时空分布特征, 并探讨了气温、降雪量、 风速等对雪深的影响, 以期为草原灾害防 灾及水资源管理提供依据和空间信息。

\section{2. 数据与方法}

\section{1 研究区概况与数据来源}

蒙古高原包括蒙古国全部地区、俄罗 斯南部地区, 以及中国内蒙古自治区和新 疆维吾尔自治区的部分地区, 本文选取内 蒙古自治区和蒙古国组成的蒙古高原主体 部分 (图 1)。主要地貌类型为高平原和山地,

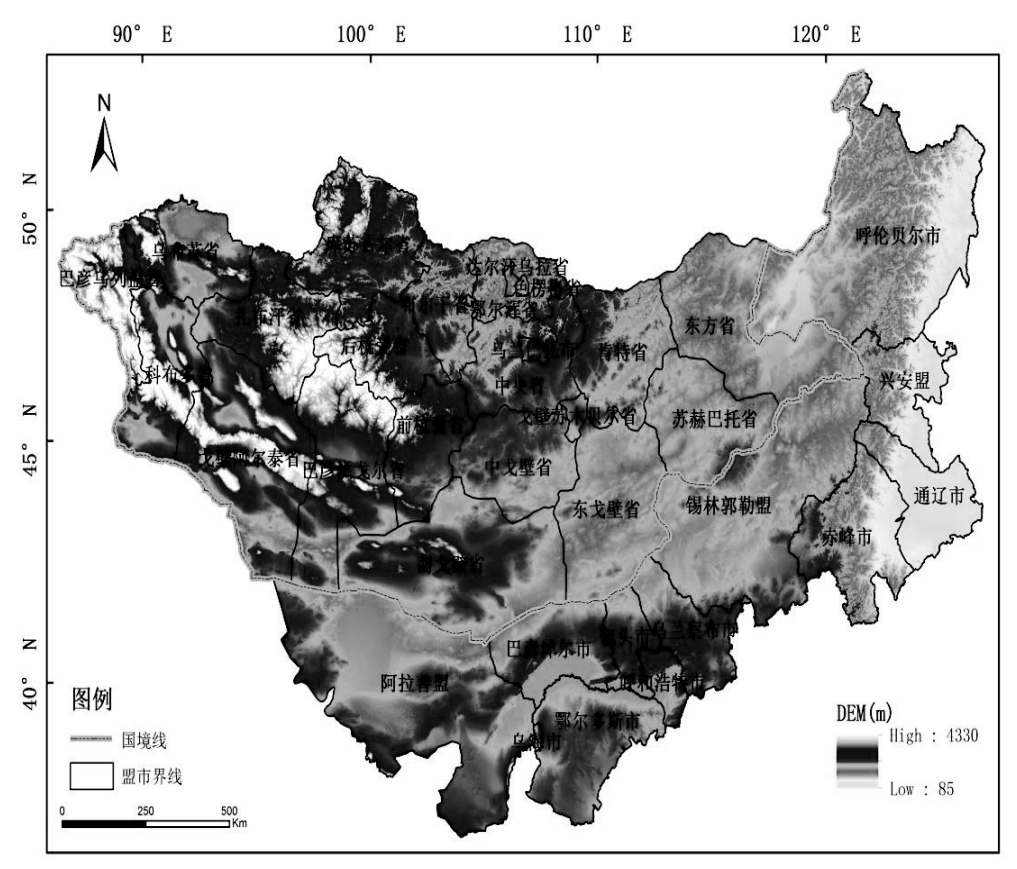

图 1 蒙古高原地理位置图 
地势从东到西逐渐升高, 东西部分别是大 兴安岭和阿尔泰山脉, 北部为萨彦岭、肯 特山脉, 南部为阴山山脉。该地区属典型 的大陆性气候, 年降水量少、干旱、冬季 春季多风 ${ }^{[8]}$ 。大部分地区年平均降水量为 $200 \mathrm{~mm}$, 东部、北部及北部山区可达到 $400 \mathrm{~mm}$ 以上。

雪深数据和气象数据 (气温、降水和风 速) 均来源于欧洲中期天气预报中心 ECMWF, 本文选择每日 4 次的 NetCDF4 格网数据, 其空间分辨率为 $0.5^{\circ} \times 0.5^{\circ}$ 。借助 Matlab 进行数据格式转换和重投影, 同时采用最 大合成法 (maximum value composite, MVC）得到蒙古高原地区 1980-2015 年逐月 雪数据。定义每年 10 月至次年 3 月作为一 个积雪季节 ${ }^{[9]}$ (如 1980 年 10 月至 1981 年 3 月为 1981 年的积雪季, 其它年份依此类 推。

\section{2 研究方法}

\subsection{1 趋势分析}

为了全面反映研究区雪深的总体变化 特征, 采用一元线性回归分析其变化趋势, 建立雪深 $(y)$ 与时间序列 (x) 的一元线性回 归方程 $\mathrm{y}=\mathrm{ax}+\mathrm{b}$, 斜率 $\mathrm{a}$ 的大小表示雪 深随时间增加或减少趋势。

\subsection{2 异常年份分析}

本文采用以距平大于标准偏差 2 倍作 为异常, 大于标准偏差的 1.5 2 倍为接近 异常来判断分析雪深的异常特征 ${ }^{[10]}$ 。

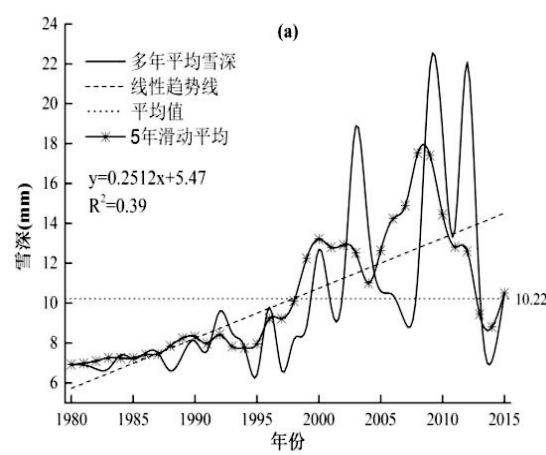

\subsubsection{Mann - Kendall 突变算法}

设原始时间序列为 $\mathrm{x}_{1}, \mathrm{x}_{2}, \cdots, \mathrm{x}_{n}$, 定义统计量 $S_{\mathrm{k}}=\sum_{i=1}^{k} r_{i} \quad(\mathrm{k}=1,2, \cdots$, n) , 其中 $r_{i}=\left\{\begin{array}{l}1, x_{i}>x_{j} \\ 0, x_{i}<x_{j}\end{array}\right.$, 在时间 序列随机独立的假设下, 定义统计量:

$$
\mathrm{UK}_{\mathrm{k}}=\frac{\left[S_{k}-E\left(S_{k}\right)\right]}{\sqrt{\operatorname{var}\left(S_{k}\right)}}(k=1,2, \ldots, n)
$$

式中, $\mathrm{UK} 1=0, \mathrm{E}(\mathrm{SK})=(\mathrm{k}(\mathrm{k}+1)) / 4, \operatorname{var}(\mathrm{SK})$ $=(\mathrm{k}(\mathrm{k}-1)(2 \mathrm{k}+5)) / 72$ 是累计 SK 的均值和方 差。将 UKK 按顺序组成一条曲线, UF=UKK, 并使 $\mathrm{UB}=-\mathrm{UKK}$ 。给定显著水平, 当 $|\mathrm{UF}|\rangle$, 表明序列存在显著趋势变化。若 UF 和 UB 出现交点, 且在临界线之间, 那么交点对 应的时刻便是突变开始的时间。UF>0 表明 序列呈上升趋势, UF $<0$ 则呈下降趋势, 当 UF 值超过显著性水平范围时, 表明上升或 下降趋势显著。

\section{3. 结果与分析}

\section{1 雪深时间变化特征}

由图 2 (a) 可知, 蒙古高原多年平均雪 深波动明显并具有阶段性变化, 雪深从 20 世纪末开始增加, 三个峰值分别出现在 2003 年、 2009 年和 2012 年。其中 2012 年 出现最大值 $22.1 \mathrm{~mm}, 1995$ 年出现最小值

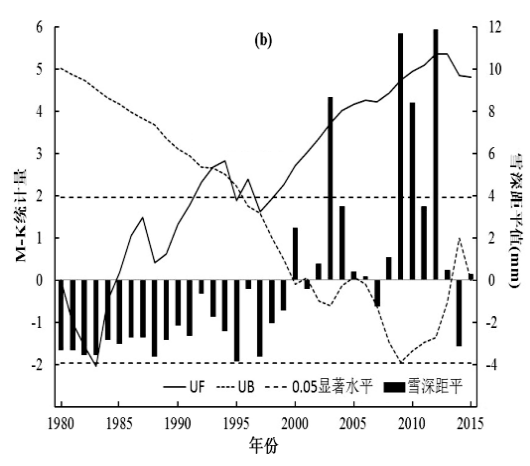

图 2 1980-2015 年蒙古高原多年平均雪深变化 (a)、雪深距平及 M-K 突变分析 (b) 
$6.4 \mathrm{~mm}$ 。线性趋势线表明蒙古高原雪深以 0. $25 / \mathrm{a}$ 的速率呈增长趋势, 多年平均值为 $10.22 \mathrm{~mm}$ 。由 5 年滑动平均可知, 20 世纪 80 年代到 90 年代中期雪深有微弱的增长趋 势但变化较为平稳, 此后近 15 年雪深明显 增加, 直至 2009 年达到最大值后呈减少趋 势, 但总体上仍呈增长趋势。

图 2 (b) 为蒙古高原雪深距平值及其 $M K$ 突变曲线, 距平可反映出对应时间内的雪 深相对于多年平均值的多少情况。从图 2(b) 可知, 蒙古高原自 20 世纪 80 年代进入相 对的少雪期, 并持续到世纪末。 21 世纪则 为多雪期, 其中 2001、2007 和 2014 年经 历了少雪期。WK 曲线表明, 1980-2015 年 之间蒙古高原雪深未发生突变, 显著性 $a<0.05$ 。但判定在上世纪 90 年代有突变的 趋势。

\section{2 雪深异常年份分析}

由表 1 平均雪深可知, 年内雪深从 10 月开始增加, 到次年 2 月达到最大值, 3 月 随着气温回升积雪开始不同程度地消融。 说明蒙古高原雪深年内变化具有单峰值特 征, 且最小值和最大值分别出现在 10 月和 2 月, 且 10 月的最小值出现在 1991 年, 2 月的最大值则在 2011 年。由线性趋势可知, 除了 10 月呈减少趋势外, 其他月份均呈增 长趋势。

异常年份的统计如表 1 所示, 雪深异 常偏多年份主要集中在 21 世纪, 尤在 2009 年之后, 说明近几年处于多雪期, 冬季应 防范雪灾。

\section{3 雪深空间分布特征}

从图 3 可知, 蒙古高原雪深具有分布 广泛且不均匀的特征。受到气候及地形影 响, 10 月 (图 3a) 蒙古国大部分地区、内 蒙古大兴安岭以及锡林郭勒盟东部开始不 同程度地降雪但雪深小于 $3 \mathrm{~mm}$, 且蒙古国北 部地区及内蒙古东部地区的雪深大于其他 地区；11月（图 3b）蒙古国巴彦乌列盖省、 库苏古尔省及内蒙古呼伦贝尔市北部地区 积雪较深达 $12 \mathrm{~mm}$, 内蒙古中部、东部雪深 逐渐增加; 12 月 (图 3c) 雪深范围在 6.9$24 \mathrm{~mm}$, 其中蒙古国北部及内蒙古东北部雪 深达到 $24.2 \mathrm{~mm} ; 1$ 月 (图 3d) 整体上积雪 较深, 西南部内蒙古阿拉善盟地区的雪深 在 1 月达到了最大值为 $9.6 \mathrm{~mm}$, 其他地区最 深达 $31.7 \mathrm{~mm}$; 随着气温降低及降雪量增加, 2 月 (图 3e) 雪深在内蒙古呼伦贝尔市北 部达到积雪季中的最大值 $37 \mathrm{~mm}$, 蒙古国西 北部、北部地区积雪较深, 西南部地区积 雪比 1 月的较浅, 最低值 $9.4 \mathrm{~mm} ; 3$ 月 (图 $3 \mathrm{f})$ 积雪开始消融, 蒙古高原北部、东北 部地区以及西南部的积雪深度明显减少, 主要是蒙古国东方省、苏赫巴托省中部、 内蒙古锡林郭勒盟东北部及阿拉善盟地区, 最小值 $6.5 \mathrm{~mm}$; 大兴安岭北部最深达 $33.8 \mathrm{~mm}$, 均比 2 月的低。总体上, 蒙古高 原雪深呈由南向北、由西向东增加的特征。

由图 $3(\mathrm{~g})$ 可知, 蒙古高原多年平均雪 深整体呈现出北部深、南部浅的分布特征。 如扎布汗省、呼伦贝尔市积雪较深, 而阿 拉善盟较浅。因北部地区地形以山脉为主 (蒙古国的杭爱山、阿尔泰山脉、内蒙古 大兴安岭), 海拔较高, 雪深分布在 $>16 \mathrm{~mm}$,

表 1 雪深线性趋势及异常年份分析

\begin{tabular}{|c|c|c|c|c|}
\hline 时段 & $\begin{array}{c}\text { 平均雪深 } \\
(\mathrm{mm})\end{array}$ & 线性趋势 (mm/a) & 接近异常 (+) & 异常 (+) \\
\hline 积雪季平均 & 10.22 & 0.25 & 2010 & 2003, 2009, 2012 \\
\hline 10 月 & 1.5 & -0.0003 & 1981, 1987 & 2012 \\
\hline 11 月 & 5.5 & 0.07 & 2000, 2003 & 2009, 2012 \\
\hline 12 月 & 11 & 0.21 & 2009 & 2003, 2012 \\
\hline 1 月 & 14.6 & 0.38 & 2004 & 2011, 2012, 2013 \\
\hline 2 月 & 15.6 & 0.47 & 2004, 2011 & 2010, 2013 \\
\hline 3 月 & 12.4 & 0.41 & 2013 & 2004, 2010, 2011 \\
\hline
\end{tabular}



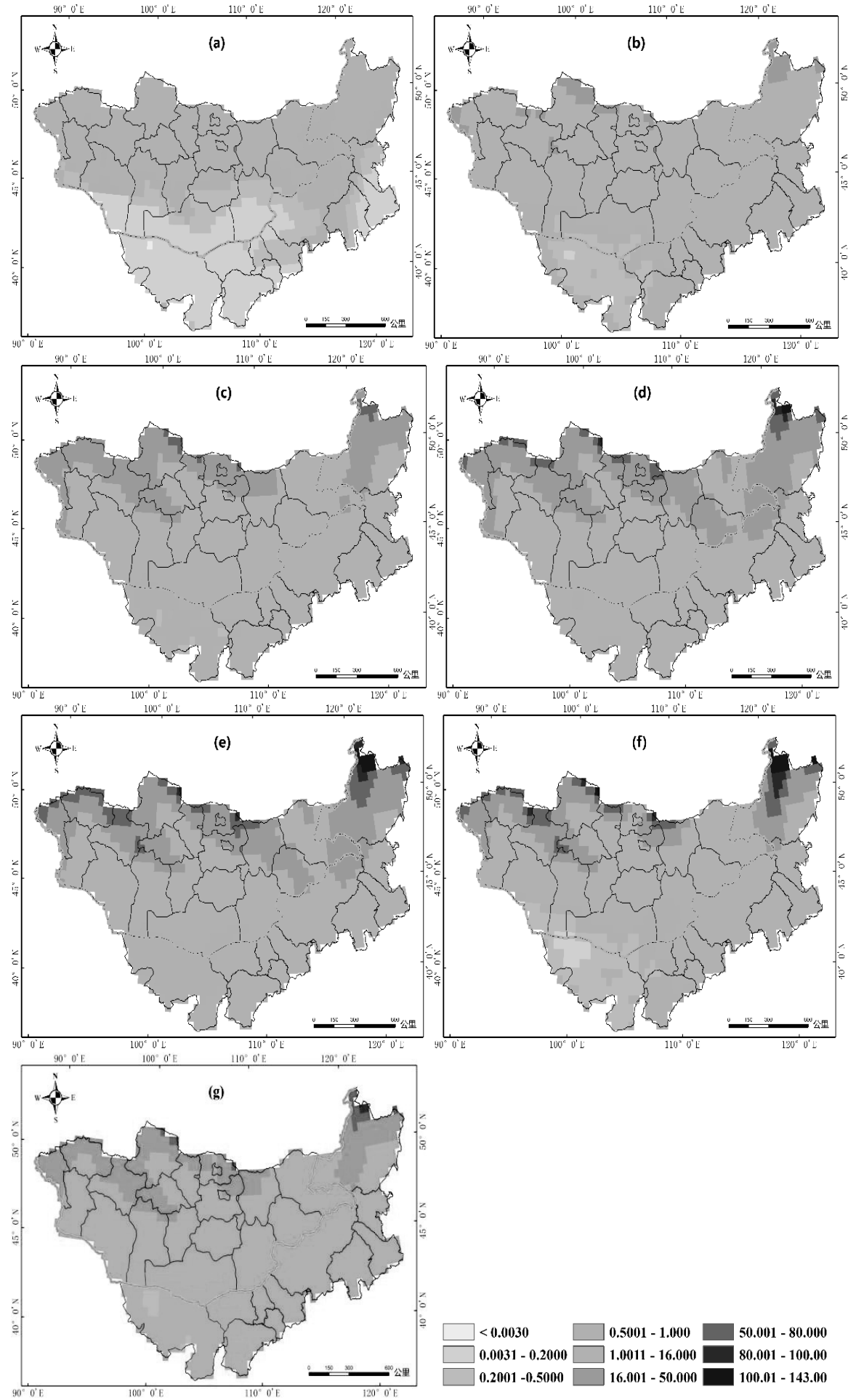

图 3 1980-2015 年蒙古高原多年平均 10 月 (a)、11 月 (b)、12 月 (c)、 1 月 (d)、2 月 (e)、3 月 (f) 及年 $(\mathrm{g})$ 平均雪深分布 (单位: $\mathrm{mm}$ )。 
占全区 19\%。阿拉善盟地区地貌类型以沙漠 戈壁及低山丘陵为主 (巴丹吉林沙漠), 不 利于积雪, 雪深分布在 $<1 \mathrm{~mm}$; 其他地区为

平坦草原地区, 雪深分布在 1-16 mm 间, 占全区 $81 \%$ 。年平均雪深最深出现在呼伦贝 尔市北部达 $22.1 \mathrm{~mm}$; 最浅出现在阿拉善盟 西部为 $6.4 \mathrm{~mm}$ 。

\section{4. 雪深影响因素探讨}

本文在分析蒙古高原雪深时空分布特征及 其变化的基础上, 结合气温、降水/雪量和 风速探讨其对雪深分布的影响。采用蒙古 高原 170 个站点的月、年平均气温、降水/ 雪量和风速与雪深进行相关性分析, 结果 如表 2 所示。(相关性结果由对应时段的雪 深和气象因子得到, 如 10 月的雪深与 10 月的气象因子计算相关性)

由表 2 可知, 雪深与气温呈负相关关 系, 其可能原因在于气温的高低影响积雪 融化情况及持续的天数。与冬季降雪量呈 正相关关系, 雪深随着降水 (雪) 量的增 大而增大。与风速呈正相关关系, 风吹雪
他月份均呈增长趋势。

（2）雪深异常偏多年份主要集中在 21 世纪, 尤在 2009 年之后, 说明近几年处于 多雪期, 冬季应注意防范雪灾。

（3）空间上，蒙古高原多年平均雪深 整体呈现出北部深、南部浅的分布特征。 内蒙古大兴安岭、锡林郭勒盟东北部、蒙 古国库苏古尔省和扎布汗省积雪较深, 阿 拉善盟雪深始终较浅。

（4）蒙古高原雪深主要受气温和降水 的影响。

本研究可为牧区雪灾评价及牧草返青 期预算提供依据, 对农业生产也有重要意 义。然而雪深与气候因子的关系比较复杂, 由于研究尺度、数据及方法的差异, 导致 结果的差异。雪深的分布应是前期秋末积 雪分布状况、当季降雪、当季积雪融化情 况 ${ }^{[12]}$ 、风吹雪、地形以及一次降雪之后的 密实化过程等因素共同作用的结果。本文 仍存在很多不足之处, 还需进一步完善得 到更精确的结论。

表 2 雪深与气候因子相关性分析结果 $(\mathrm{a}<0.05)$

\begin{tabular}{cccc}
\hline 时段 & 气温 & 降水/雪量 & 风速 \\
\hline 积雪季平均 & -0.21 & -0.05 & 0.02 \\
10 月 & -0.29 & $0.38 *$ & $0.33 *$ \\
11 月 & $-0.44 *$ & $0.67 *$ & 0.15 \\
12 月 & $-0.36 *$ & 0.26 & 0.13 \\
1 月 & $-0.38 *$ & 0.14 & -0.06 \\
2 月 & -0.17 & -0.02 & 0.28 \\
3 月 & -0.17 & -0.28 & $0.46 *$ \\
\hline
\end{tabular}

可使得积雪重新分配, 此外, 大风天气常 伴随着降温, 导致积雪较难融化。说明雪 深主要受气温和降水影响, 这与胡豪然等 的结论一致 ${ }^{[11]}$ 。

\section{5. 结论}

蒙古高原作为北半球关键区位, 该区 的积雪对生态环境、农牧业发展具有重要 作用。本文以 ECMWF 再分析数据为基础, 分析了蒙古高原 1980-2015 年雪深时空变 化特征, 并得出以下主要结论:

（1）时间上，蒙古高原多年平均雪深以 $0.25 \mathrm{~mm} / \mathrm{a}$ 的增长率呈增长趋势, 但没有明 显的突变点。年内最大雪深出现在 2 月, 最小值出现在 10 月, 且除 10 月以外, 其

\section{Acknowledgements}

This study was supported by the Innovation team of disaster prevention and mitigation of grassland non biological disasters in Chinese Academy of Agricultural Sciences (CAASASTIP-IGR 2016-0406), the Natural Science Foundation(41561099), the Natural Science Foundation of Inner Mongolia (No.2016MS04 09), Inner Mongolia science and technology project(201502095), and(201702116).

\section{致谢}

本研究得到了中国农业科学院草原非生物 灾害防灾减灾创新团队项目 (CAAS-ASTIPIGR 2016-0406），国家自然科学重点基金 
(61631011)，内蒙古自然科学基金项目 (2016US0409)，内蒙古科技计划项目 （201702116）的资助。

\section{参考文献}

[1] 刘宝河,左合君,董智,等.一次降雪的积 雪密实化过程研究.干旱区资源与环 境,2017,31(01):178-184.

[2] 哈斯,张继权, 郭恩亮, 等. 内蒙古呼伦贝 尔地区积雪面积时空演变规律研究. 风 险分析和危机反应中的信息技术--中国 灾害防御协会风险分析专业委员会年 会. 2014.

[3] Huang X, Deng J, Wang W, et al. Impact of climate and elevation on snow cover using integrated remote sensing snow products in Tibetan Plateau. Remote Sensing of Environment, 2017, 190:274288.

[4] 戴声佩,张勃,程峰, 等. 基于被动微波遥 感反演雪深的时间序列分析我国积雪 时空变化特征. 冰川冻土, 2010,32(6): 1066-1073.

[5] 王芹芹. 新疆内陆河流域积雪深度变化 规律的分析与研究. 甘肃水利水电技术,
2014, 50(3):9-11.

[6] 王国强,秦富仓, 岳永杰. 满洲里市积雪 动态变化及其与主要气侯因子的关系 分析. 内蒙古农业大学学报(自然科学 版), 2011, 32(4):71-74.

[7] 余予. ECMWF 全球实地观测积雪历史 数据集研讨会简介. 气象科技合作动态, 2015(3):27-30.

８］包刚,包玉海,覃志豪, 等. 近 10 年蒙古高 原植被覆盖变化及其对气候的季节响 应.地理科学,2013,33 (05) : 613-621.

[9] 萨楚拉,刘桂香,包刚,等. 近十年蒙古高 原积雪面积时空变化研究. 内蒙古师大 学报(自然汉文版),2012.41(5): 531-536.

[10] 史建桥. 基于遥感和 GIS 的青藏高原积 雪时空变化及影响因子分析. 南京信息 工程大学, 2014.

[11] 胡豪然,伍清. 近 44 年青藏高原东部积 雪的年代际变化特征及其与降雪和气 温的关系. 高原山地气象研究, 2016, 36(1):38-43.

[12] 谢静芳, 章娜, 冯瑶. 吉林省积雪深度的 影响条件分析及预报. 全国城市气象服 务科学研讨会. 2001 